\title{
Rehabilitation of Shear-Damaged Reinforced Concrete Beams Using Self-Compacting Concrete Jacketing
}

\author{
Constantin E. Chalioris and Constantin N. Pourzitidis \\ Department of Civil Engineering, Democritus University of Thrace, 67100 Xanthi, Greece \\ Correspondence should be addressed to Constantin E. Chalioris, chaliori@civil.duth.gr
}

Received 22 July 2012; Accepted 10 October 2012

Academic Editors: L. Li, S. Pantazopoulou, and Y. Zhang

Copyright ( $) 2012$ C. E. Chalioris and C. N. Pourzitidis. This is an open access article distributed under the Creative Commons Attribution License, which permits unrestricted use, distribution, and reproduction in any medium, provided the original work is properly cited.

\begin{abstract}
The application of a reinforced self-compacting concrete jacket for the structural rehabilitation of shear damaged reinforced concrete beams is experimentally investigated. Five beams were constructed and subjected to monotonic loading in order to exhibit shear failure. The damaged specimens were restored using relatively thin reinforced jackets and retested by the same four-point bending loading. The self-compacting concrete jacket applied, encasing the bottom width and both vertical sides of the initially tested beams (U-formed jacketing), has a small thickness $(25 \mathrm{~mm})$ and includes small $(\varnothing 5)$ steel bars and $U$-formed stirrups. Test results and comparisons between the experimental behaviour of the beams indicated that the examined jacketing technique is a reliable rehabilitation method since the capacity of the retrofitted beams was fully restored or ameliorated with respect to the initial specimens. Discussion of the ability of the applied jacket to enhance the overall structural performance of the examined beams and, potentially, to alter their failure mode to a more ductile one is also included. Calculations of the flexural and shear strength of the tested beams and evaluation of the monolithic factors for the capacity at yield and at ultimate of the jacketed beams were also performed and are commented on.
\end{abstract}

\section{Introduction}

One of the most commonly used rehabilitation techniques for poor detailed or damaged reinforced concrete (RC) members is the application of jackets around the structural elements. RC jacketing is a traditional and well-known upgrading technique that has proven to be the best option for engineers in earthquake-prone areas. It has long been recognized that RC jackets do provide increased strength, stiffness, and overall enhancement of the structural performance. For this reason, although common RC jacketing exhibits shortcomings, it is frequently used either prior to or after the damage of RC members, such as beams, columns, and joints $[1-5]$.

The use of a shotcrete overlay on the surface of an existing $\mathrm{RC}$ member with an outer assembled reinforcement cage has also proved to be an efficient strengthening technique. Shotcrete jacketing can be used in lieu of conventional castin-place concrete jackets because of its potential to achieve good bond strength and low permeability. It is also known that the shotcrete process is more versatile than common concrete placement and can be applied in very difficult or complex sections where conventional concrete formwork would prove difficult, cost-prohibitive, or even impossible $[2,6]$.

Moreover, the apparent disadvantages of RC (cast-inplace concrete or shotcrete) jacket applications include the labour-intensive and time-consuming procedures required. Another important drawback is the reduction of the available floor-space since jacketing increases the member sizes and also causes significant mass increase, stiffness modifications, and subsequently alteration of the dynamic characteristics of the entire structure [7].

For these reasons, even though concrete is the most frequently applied structural material for jacketing, jackets have also been constructed using steel elements, fibrereinforced-polymers (FRP), and textile-reinforced-mortars (TRM) as alternatives to RC jacketing. A variety of these 
jacketing techniques has been examined in order to upgrade beams, columns, and joints [8-11].

Although the use of FRP or steel cage jackets enhanced the response of the jacketed member in most of the examined cases, anchoring of these materials has proved to be an essential and difficult problem for the effectiveness of these techniques. It is also obvious that common constructional limitations such as spandrel beams, existence of slab, and transverse beams, especially in cases of beam-column joints, bring more difficulties to the applications of these materials. Besides, FRP failure is dominated by premature debonding of the composite material from the concrete surface and substantial reductions of the potential capability in shear strength have been reported [12].

Recently, the use of a thin and locally applied RC jacket for the rehabilitation of damaged RC beam-column connections has been proposed. The main advantage of this jacketing technique comparing to the common RC jacket is the fact that its application is not restrained by space limitations and since it only slightly changes the initial size of the elements, the building's seismic behaviour remains practically unaffected. This thin jacket consists of small diameter steel reinforcements and is made of a premixed, non-shrink, flowable, rapid, and high-strength cementbased mortar. Test results indicated that the cyclic response of the retrofitted specimens was fully restored and in some cases substantially improved with respect to the performance of the initially tested specimens [13].

Based on that success, the application of a relatively thin jacket made of self-compacting-concrete (SCC) for the rehabilitation of damaged RC beams is addressed and examined herein. It is known that SCC is a highly flowable nonsegregating concrete that spreads and fills into formwork, encapsulating even the most congested reinforcement without any mechanical vibration demand $[14,15]$.

Good workability, remarkable filling, and passing ability make SCC an optimal material for the rehabilitation of damaged concrete parts, restoring element continuity and homogeneity. Further, SCC flows through reinforcements without causing vacuums in the element or any discontinuity at the interface between existing and new concrete. Thus, SCC mixtures with high fluidity, small diameter aggregate, shrinkage offset, and high-strength are usually required in jacketing applications because of the lack of space in the jacket. This is due to its diminished thickness associated with the volume occupied by the added steel reinforcement. For the same reasons, SCC is also recommended in shear concrete elements, such as deep beams, that contain congested transverse reinforcement and recent studies have focused on the shear strength of normal and high strength SCC [16-18].

In this paper, the use of a reinforced SCC jacketing technique for the structural rehabilitation of shear-damaged RC beams is experimentally investigated. For the needs of this study, 5 RC beams were constructed and initially subjected to monotonic loading in order to exhibit shear failure mode. Afterwards, the damaged specimens were retrofitted using relatively thin SCC jackets with small diameter steel reinforcements, and were retested. Different specimen and jacketing configurations with various amounts of flexural and shear reinforcement were examined. Discussion of the test results and the ability of the applied SCC jacket to fully restore the damaged beams, to enhance the structural performance of the jacketed beams with respect to the initially tested beams, and, potentially, to alter their failure mode to a more ductile one is also included.

\section{Experimental Program}

The experimental program includes 10 monotonic fourpoint bending loading tests. First, 5 RC beams were constructed and initially tested and damaged in shear. After their rehabilitation using reinforced SCC jackets, these 5 jacketed beams were retested under the same loading. Supplementary compression and splitting tests of the commonly used concrete of the initial beams and the SCC of the jackets, along with tensile tests of the steel reinforcing bars of the specimens, are also included in the research program.

2.1. Characteristics of the Initial Beams. All beams had the same overall length $(1.6 \mathrm{~m})$ and rectangular cross-section. The cross-sectional dimensions were 200/300 mm (specimen B1) and 125/200 mm (specimens B2, B3, B4, and B5). Geometrical and mechanical characteristics of the initially tested beams are presented in Table 1. Steel reinforcement comprised longitudinal deformed bars with diameters of $\varnothing 8$ or $\varnothing 16$ at the top and at the bottom of the beams' crosssection and mild steel closed stirrups with a diameter of $\varnothing 5$. Reinforcement arrangement of the specimens is shown schematically in Figure 1 and summarized in Table 1 in terms of longitudinal and transverse reinforcement ratios. The mean concrete compressive and tensile strength of each beam were measured from compression and splitting tests of cylinders, respectively, and are presented in Table 1 . The stress-strain curves of the used steel bars and stirrups are demonstrated in Figure 2, as measured from steel tensile tests.

Beams were designed in order to exhibit shear failure mode. For this reason an inadequate amount of stirrups has been provided in the initial beams. It is mentioned that specimen B1 is a short beam and has no transverse reinforcement.

2.2. Rehabilitation Procedure and Characteristics of the Jacketed Beams. After the initial loading, the shear-damaged beams were rehabilitated using relatively thin reinforced jackets made of SCC. The thickness of the jackets was $25 \mathrm{~mm}$. Details of the jacketing scheme are shown in Figure 3. Jackets encased the bottom width and both vertical sides of the damaged beams (U-formed jacketing). The steel reinforcement of the jackets consists of small (Ø5) mild steel straight bars and U-formed stirrups, as displayed in Figures 1 and 3. The geometrical and reinforcement characteristics of the jacketed beams are also presented in Table 2. It is mentioned that the values in the last two columns of Table 2 represent the total amount of the tensional longitudinal and the transverse reinforcement ratios (sum of the steel reinforcement of the initial beam and of the jacket). 
TABLE 1: Geometrical, mechanical, and steel reinforcement characteristics of the initial beams.

\begin{tabular}{lcccccccccccc}
\hline Beam name & $b / h(\mathrm{~mm})$ & $d(\mathrm{~mm})$ & $a / d$ & \multicolumn{4}{c}{ Longitudinal bars } & Stirrups & $\begin{array}{c}f_{c, \text { cyl }} \\
(\mathrm{MPa})\end{array}$ & $\begin{array}{c}f_{\text {ct,split }} \\
(\mathrm{MPa})\end{array}$ \\
\hline B1 & $200 / 300$ & 275 & 2.18 & $3 \varnothing 16$ & $1.10 \%$ & $3 \varnothing 16$ & $1.10 \%$ & - & - & 26.2 & 2.10 \\
B2 & $125 / 200$ & 175 & 3.43 & $4 \varnothing 8$ & $0.92 \%$ & $2 \varnothing 8$ & $0.46 \%$ & $\varnothing 5 / 300$ & $0.10 \%$ & 28.2 & 2.15 \\
B3 & $125 / 200$ & 175 & 3.43 & $2 \varnothing 8$ & $0.46 \%$ & $4 \varnothing 8$ & $0.92 \%$ & $\varnothing 5 / 300$ & $0.10 \%$ & 27.2 & 2.20 \\
B4 & $125 / 200$ & 175 & 3.43 & $4 \varnothing 8$ & $0.92 \%$ & $4 \varnothing 8$ & $0.92 \%$ & $\varnothing 5 / 200$ & $0.16 \%$ & 23.4 & 2.05 \\
B5 & $125 / 200$ & 175 & 3.43 & $2 \varnothing 8$ & $0.46 \%$ & $4 \varnothing 8$ & $0.92 \%$ & $\varnothing 5 / 150$ & $0.21 \%$ & 23.8 & 1.95 \\
\hline
\end{tabular}

The objective of the SCC jacketing design was twofold; first to fully restore the shear-damaged beams, and secondly to increase the amount of reinforcement provided, focused on the shear reinforcement, in order to enhance the structural capability of the jacketed beams with respect to the initially tested beams and, potentially, to alter their failure mode to a more ductile one. For this reason, the supplementary flexural reinforcement ratio of the jackets is rather low and varied between $0.11 \%$ and $0.22 \%$ for the tension bars, whereas the shear reinforcement ratio of the jackets is higher and varied between $0.15 \%$ and $0.63 \%$. These ratios have been calculated based on the total cross-sectional dimensions of the jacketed beams. It is emphasized that the added steel transverse reinforcement of the jacketed beam B1-J is very dense $(\varnothing 5 / 25 \mathrm{~mm})$ since it is a deep beam, the initial beam B1 had no stirrups and a substantial increase of the shear strength should be achieved in the retrofitted beam. Based on the total amount of the reinforcement and the mechanical and the geometrical characteristics of the retrofitted beams, their overall performance was expected to be ameliorated.

It is noted that initially tested beams sustained severe shear-damage, spalling of concrete cover, and intense diagonal cracking. All the loose concrete fragments were completely removed and the missing parts of the beams reconstructed by jacketing reformed and recasted by SCC as described below. Beam B5 experienced the most substantial damage and a rather large concrete part has been removed along with the stirrup that fractured during the test (Figure 4(e)). No special roughening of the surface of the damaged beams was performed prior to jacketing construction.

L-shaped mild steel dowels with $5 \mathrm{~mm}$ diameter were installed in the vertical sides of the initial beams in order to support the longitudinal bars of the jacket. Dowels were bonded by injected epoxy resin into $7 \mathrm{~mm}$ holes that were drilled in advance. The number of dowels provided was rather low; every side bar of the jacket had $\varnothing 5$ dowels per approximately $300 \mathrm{~mm}$ in beam B1-J, $200 \mathrm{~mm}$ in beam B2$\mathrm{J}$ and $150 \mathrm{~mm}$ in beams B3-J, B4-J, and B5-J. No dowels have been installed at the bottom bars of the jackets. The main reason of the low number of steel dowels provided is that the initially tested beams suffered severe cracking and the installation of numerous dowels by drilling may further deteriorate these damages. Steel bars, stirrups, and dowels of the jacketed beams B2-J, B3-J, B4-J, and B5-J were all welded together. Welding only between dowels and bars was performed in specimen B1-J. It is also mentioned that the steel stirrup of the damaged beam B5 that was fractured during initial loading was replaced by a new one with the same characteristics as the old one prior to installation of the jacketing reinforcement. Steel reinforcement details of the jackets are also shown in the photographs of Figure 4.

Cast-in-place SCC was used to complete the rehabilitation procedure of the damaged beams (see also the jacketing formwork and the pouring procedure in the photographs of Figure 5). Mix proportions for casting one cubic meter of SCC are summarized in Table 3 . Cement containing $305 \mathrm{~kg}$ of CEM IV (W-P)/B $32.5 \mathrm{~N}$ type cement and $51 \mathrm{~kg}$ of CEM II $42.5 \mathrm{~N}$ type cement was used. Further, fine aggregates (sand) and coarse aggregates with maximum diameter of $8 \mathrm{~mm}$ were also used in the SCC mixture. Superplasticizer (Glenium 21), retarder (Pozzolith $134 \mathrm{CF}$ ), and viscositymodifying admixture (VMA) were also added in order to bring the required water reduction and fluidity, and to increase cohesion and segregation resistance [19]. The mean SCC cylinder compressive and splitting tensile strength used for each jacketed specimen is presented in Table 4.

After SCC pouring, the final result was generally good. Limited superficial imperfections were observed after jacketing formwork stripping and they were fixed using highstrength, low-shrinkage, and rapid-hardening cement paste (EMACO S55) [20].

2.3. Test Setup. All beams were tested in monotonically increasing loading up to total failure. The experimental setup is shown in Figure 1 [21]. Beams were edge-supported on roller supports using a rigid laboratory frame. The imposed loading was applied using a steel spreader beam in two points in the midspan of the beams adopting a four-point bending scheme with a shear span of $a=600 \mathrm{~mm}$. The span-to-depth ratio $(a / d)$ represents the shear to moment interaction and its values for the initial and the jacketed beams are reported in Tables 1 and 2, respectively.

Loading was imposed consistently by a pinned-end actuator and measured by a load cell with an accuracy of $0.05 \mathrm{kN}$. The net midspan deflections of the tested beams were recorded by three LVDTs with $0.01 \mathrm{~mm}$ accuracy. One of them was placed in the midspan of the beams and the other two in the supports (see also Figure 1). Measurements of load and corresponding deflections were read and recorded continuously during the tests. 

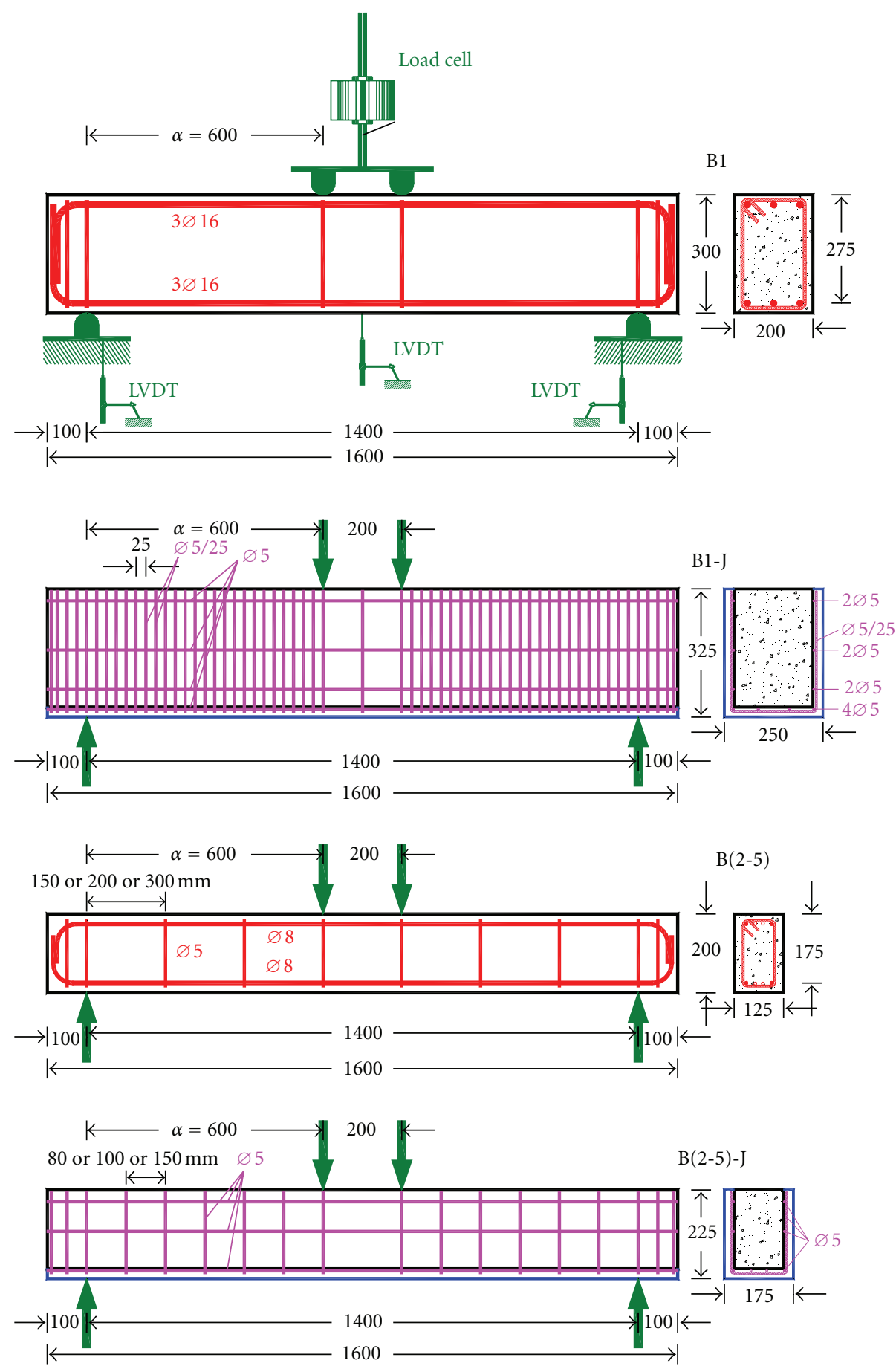

FIGURE 1: Geometry, test setup, and steel reinforcement arrangement of the tested beams (dimensions are given in mm).

\section{Test Results and Discussions}

3.1. Strength and Behaviour. The experimental behaviour of the initial and the jacketed beams in terms of applied load versus midspan deflection curves is presented and compared in Figure 6. Values of the measured load at yield point $\left(P_{y, \exp }\right)$, if any were observed, and at maximum capacity $\left(P_{\max , \exp }\right)$ of the tested beams are also reported in Table 5.
From these load values and the behavioural curves of Figure 6 a significant improvement of the loading bearing capacity of all the retrofitted beams with respect to the corresponding initially tested beams can be observed. This increase of the maximum applied load is also presented in Table 5 in the experimental values of the load increase due to the jacketing $\left(P_{\text {jack }}\right)$ and varied approximately from $35 \%$ (in beam B5-J) to $200 \%$ (in beam B1-J). 
TABLE 2: Geometrical and steel reinforcement characteristics of the jacketed beams.

\begin{tabular}{|c|c|c|c|c|c|c|c|c|c|c|c|c|c|}
\hline \multirow{3}{*}{$\begin{array}{l}\text { Beam name } \\
\text { B1-J }\end{array}$} & \multirow{3}{*}{$\begin{array}{c}\begin{array}{c}b / h \\
(\mathrm{~mm})\end{array} \\
250 / 325\end{array}$} & \multirow{3}{*}{$\frac{d(\mathrm{~mm})}{305}$} & \multirow{3}{*}{$\begin{array}{c}a / d \\
1.97\end{array}$} & \multicolumn{6}{|c|}{ Longitudinal bars of the jacket } & \multirow{2}{*}{\multicolumn{2}{|c|}{$\begin{array}{l}\text { U-formed stirrups } \\
\text { of the jacket }\end{array}$}} & \multicolumn{2}{|c|}{ Total reinf. } \\
\hline & & & & \multicolumn{2}{|c|}{$\mathrm{Up}$} & \multicolumn{2}{|c|}{ Middle } & \multicolumn{2}{|c|}{ Bottom } & & & \multirow{2}{*}{$\begin{array}{c}\rho_{\ell, \text { tens }} \\
0.95 \%\end{array}$} & \multirow{2}{*}{$\frac{\rho_{t}}{0.63 \%}$} \\
\hline & & & & $2 \varnothing 5$ & $0.05 \%$ & $2 \varnothing 5$ & $0.05 \%$ & $2+4 \varnothing 5$ & $0.15 \%$ & & & & \\
\hline D2 & & 205 & 2.93 & $2 \varnothing 5$ & & $2 \varnothing 5$ & & $4 \varnothing 5$ & & & & $0.50 \%$ & $0.22 \%$ \\
\hline 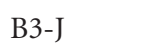 & 1520 & 205 & 2.93 & $2 \varnothing 5$ & $0.11 \%$ & $2 \varnothing 5$ & & $2 \varnothing 5$ & & & & $0.67 \%$ & $0.36 \%$ \\
\hline B4-J & 751225 & 205 & 2.93 & $2 \varnothing 5$ & $0.11 \%$ & $2 \varnothing 5$ & $0.11 \%$ & $2 \varnothing 5$ & $0.11 \%$ & $\varnothing 5 / 100$ & $0.22 \%$ & $0.67 \%$ & $0.34 \%$ \\
\hline B5-J & $175 / 225$ & 205 & 2.93 & $2 \varnothing 5$ & $0.11 \%$ & $2 \varnothing 5$ & $0.11 \%$ & $2 \varnothing 5$ & $0.11 \%$ & $\varnothing 5 / 100$ & $0.22 \%$ & $0.67 \%$ & $0.37 \%$ \\
\hline
\end{tabular}

TABLE 3: Mix proportions of SCC.

\begin{tabular}{|c|c|c|c|c|c|c|c|}
\hline Cement & Water & Fine aggregate & Coarse aggregate & Filler & Superplasticizer & Retarder & VMA \\
\hline 1 & 0.54 & 2.48 & 2.25 & 0.28 & 0.0335 & 0.0032 & 0.0012 \\
\hline
\end{tabular}

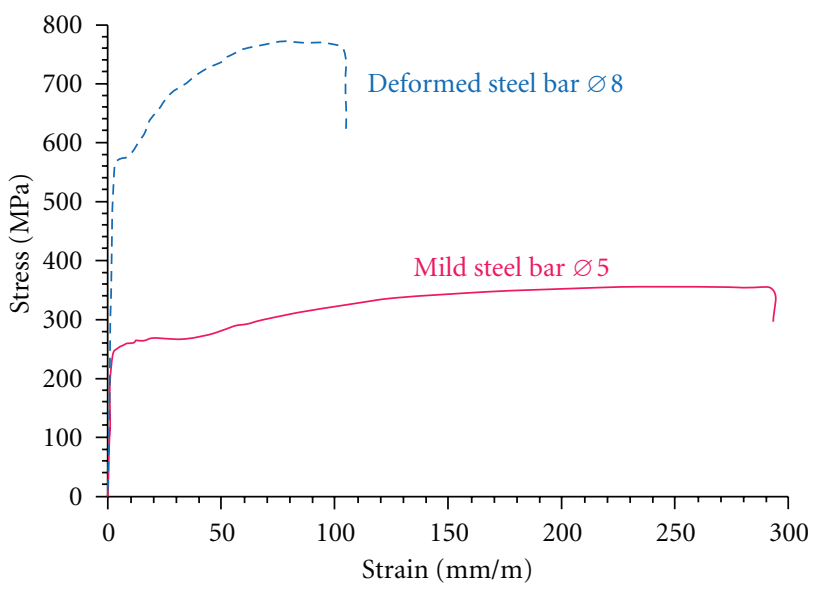

FIGURE 2: Stress-strain curves of the used steel reinforcement.

TABLE 4: Mean compressive and splitting tensile strength of SCC.

\begin{tabular}{llllll}
\hline Jacket of beam: & B1-J & B2-J & B3-J & B4-J & B5-J \\
\hline Compressive strength (MPa) & 43.9 & 42.8 & 40.5 & 40.0 & 39.8 \\
Tensile splitting strength (MPa) & 3.54 & 3.72 & 3.47 & 3.25 & 3.32 \\
\hline
\end{tabular}

Further, the overall structural performance of the jacketed beams is substantially ameliorated regarding the initial shear-damaged specimens in most of the examined cases (see also the behavioural curves of Figure 6). Jacketed beams B3-J, B4-J, and B5-J exhibited pure flexural behaviour whereas the corresponding initially tested beams B3, B4, and B5 demonstrated typical brittle shear response. In order to quantitatively evaluate this advance, the values of the displacement ductility $\left(\Delta_{\max } / \Delta_{y}\right)$ that expresses the ratio of the deflection at failure $\left(\Delta_{\max }\right)$ to the deflection at yield point $\left(\Delta_{y}\right)$ of the beam are presented in Table 5 . From these values, the enhanced ductile behaviour of the aforementioned jacketed beams is clearly confirmed.
3.2. Cracking Patterns and Failure Modes. The cracking patterns at failure of the tested beams are displayed in the photographs of Figure 7. From this Figure it can be observed that all the initially tested specimens exhibited diagonal cracking and quite brittle shear failure (see the five left-hand photographs in Figure 7). A rather minor exception on this observation is the case of beam B2 that demonstrated a rather combined failure mode of flexure and shear. Tension bars of beam B2 yielded and a short flexural response is firstly observed. However, shear failure inevitably occurred due to the inadequate amount of the transverse reinforcement and beam B2 experienced severe diagonal cracking between the stirrups. The observed failure mode of each initially tested beam is also presented in Table 5. It is also noted that shear failure of specimen B5 occurred due to the fracture of both vertical legs of the steel stirrup of the beam.

On the other hand, jacketed beams B3-J, B4-J, and B5-J exhibited ductile flexural failure mode (see the right photographs in Figure 7). During the retest, these specimens developed flexural cracks and showed an increasing postyield behaviour up to the ultimate capacity and the final top concrete compressive zone failure (see also Figures 8(b) and 8(c)). Jacketed beam B2-J demonstrated a combined failure mode of flexure and shear, alike to that of the corresponding initial beam B2. In the beginning, flexural cracking was observed and the bottom steel bars yielded. However, at the end, beam B2-J failed under shear due to the fracture of the U-formed stirrup of the jacket (see also Figure 8(a)).

Jacketed beam B1-J exhibited intense diagonal cracking, brittle shear failure, and abrupt collapse. It is emphasized that although the ultimate capacity of beam B1-J was increased approximately 3 times with respect to the corresponding initially tested beam B1, both beams displayed shear failure and diagonal crack at the same position. This may be attributed to the low value of the span-to-depth ratio of the jacketed beam $(a / d=1.97<2.5)$ that is a typical characteristic of a deep beam that usually exhibits shearcompression failure. Besides, it is known that span-to-depth ratio is a primary design parameter that significantly affects 


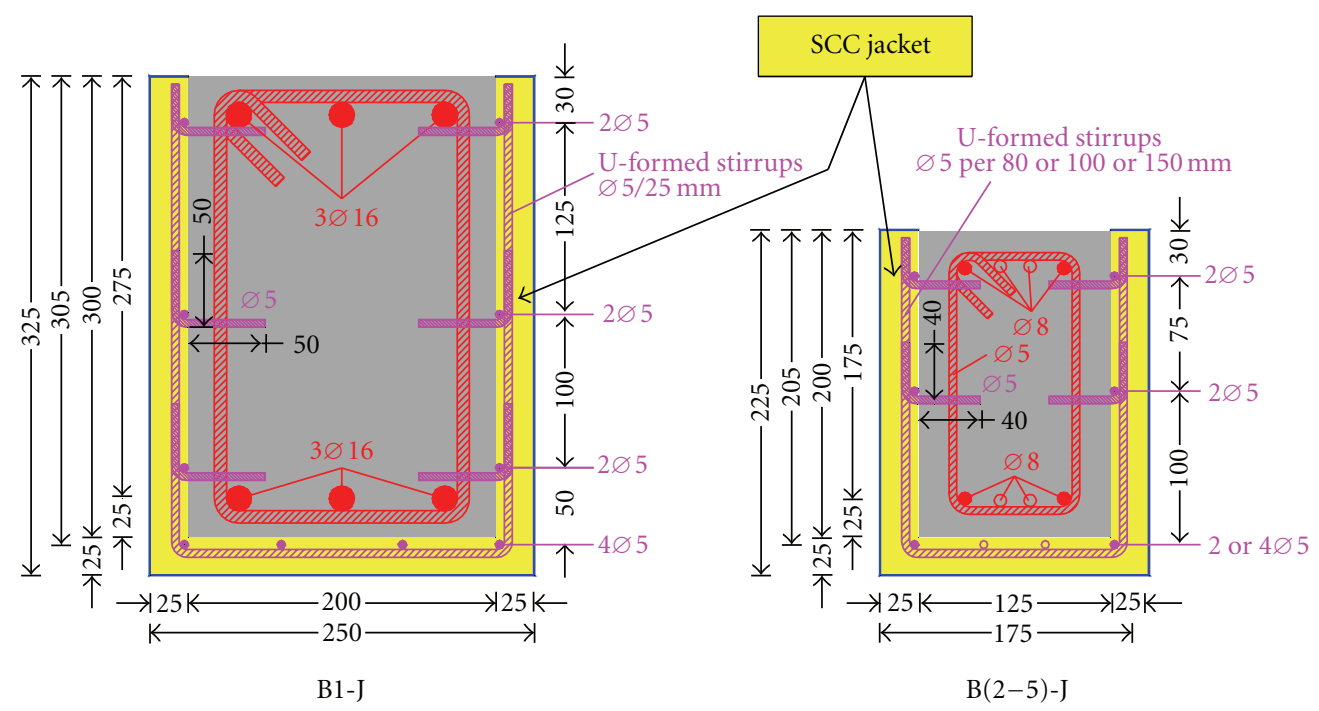

FIgURE 3: Cross-sectional dimensions and steel reinforcement arrangement of the jacketed beams (dimensions are given in mm).

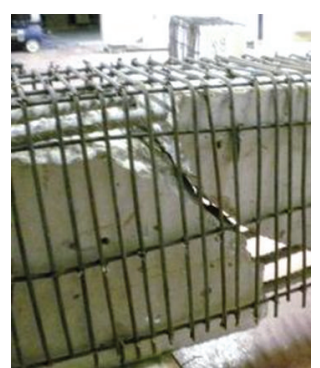

(Side view)

(a) B1-J

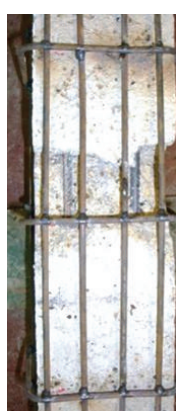

(b) B2-J

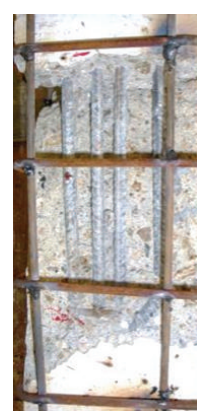

(c) B3-J

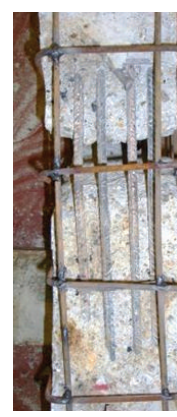

(d) B4-J

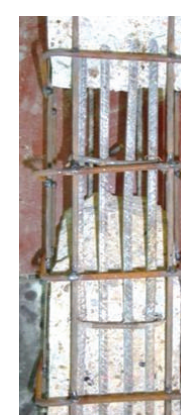

(e) B5-J

FIGURE 4: Steel reinforcement of the jackets (views from the bottom).

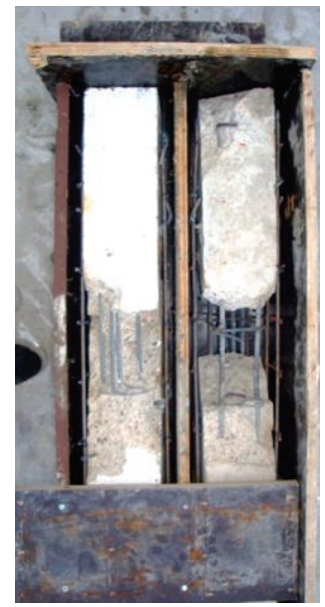

(a)

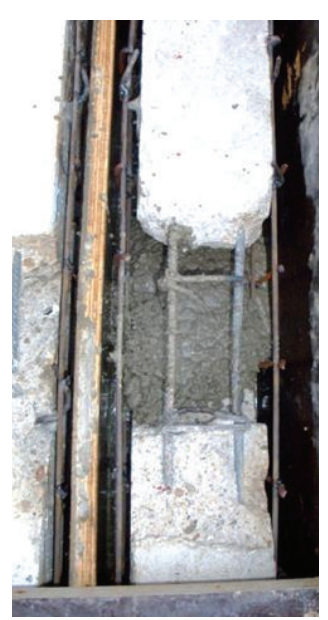

(b)

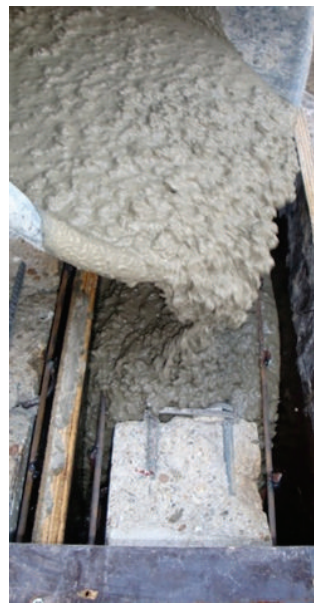

(c)

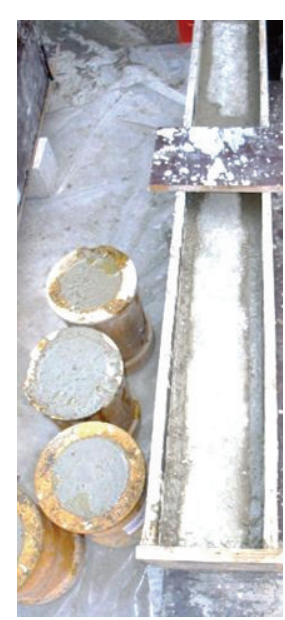

(d)

FIGURE 5: Jacketing formwork and SCC pouring. 


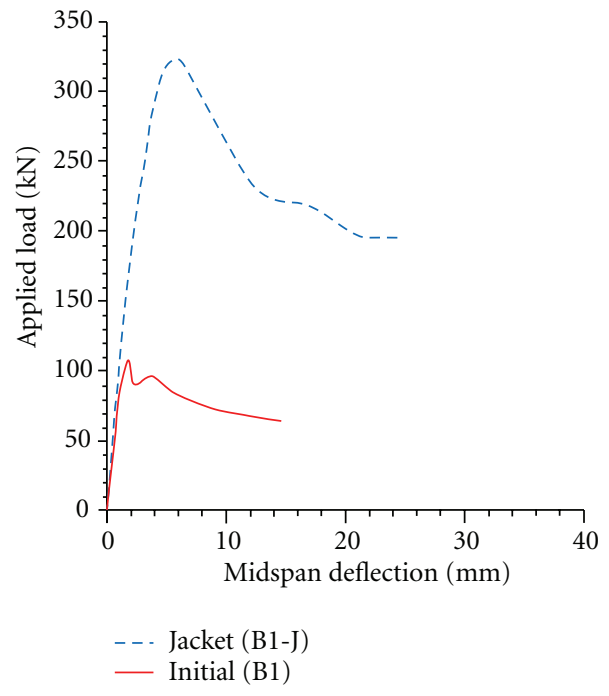

(a)

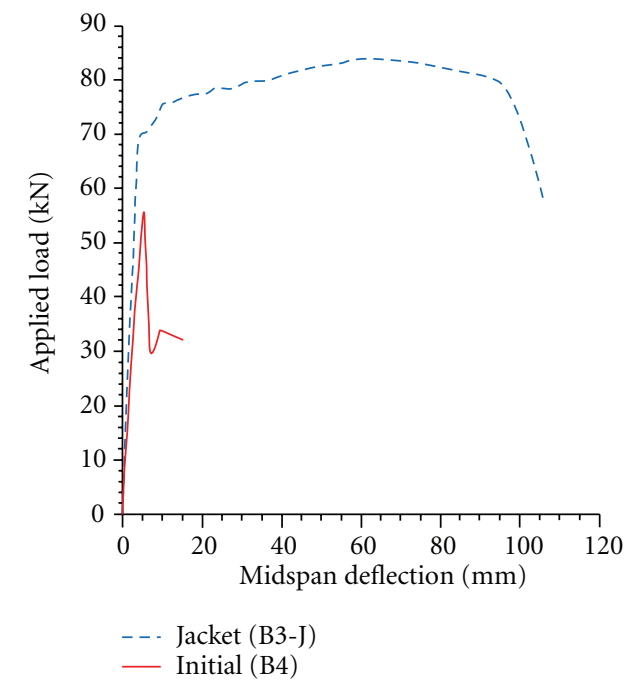

(c)

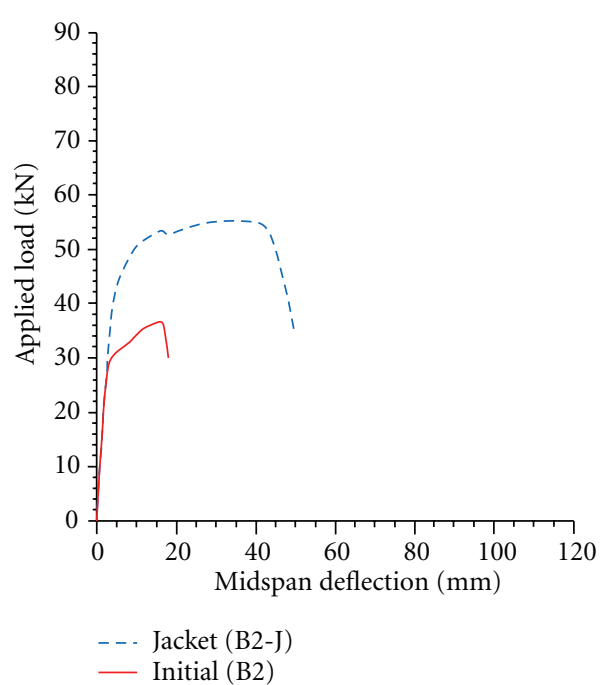

(b)

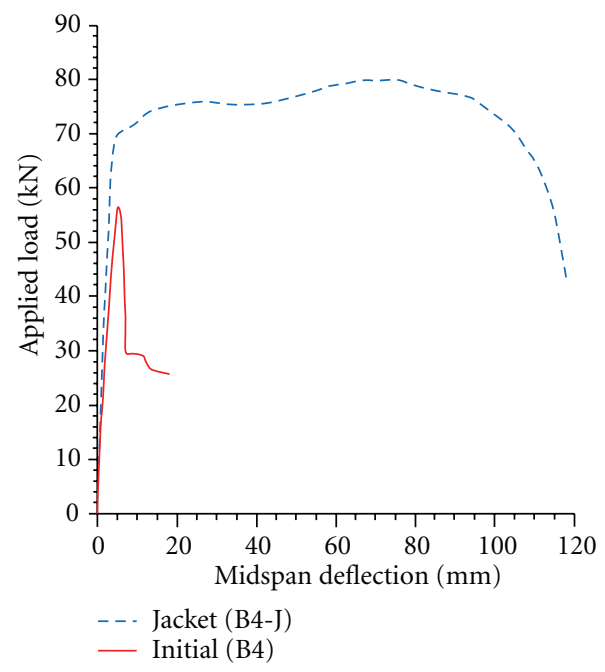

(d)

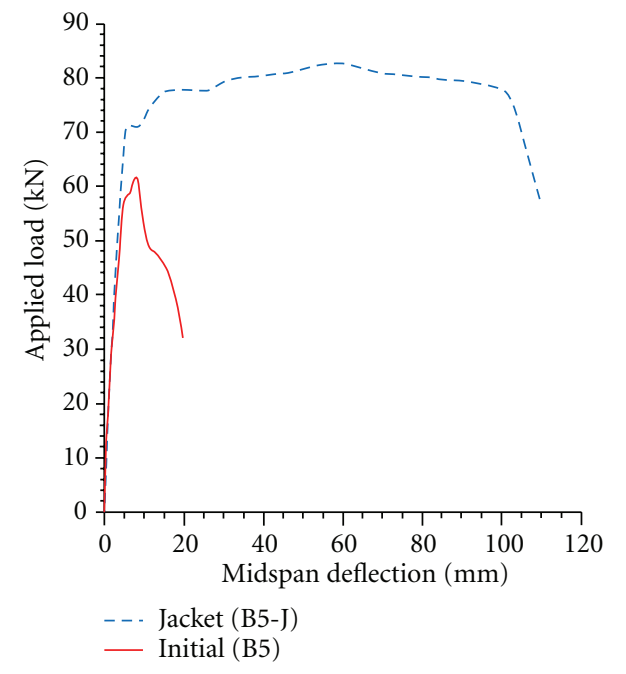

(e)

FIgURE 6: Experimental behaviour of the tested beams. 
TABLE 5: Experimental results.

\begin{tabular}{lccccc}
\hline Beam name & $P_{\text {y,exp }}(\mathrm{kN})$ & $P_{\max , \exp }(\mathrm{kN})$ & $P_{\text {jack }}(\mathrm{kN})$ & $\Delta_{\max } / \Delta_{y}$ & $\begin{array}{c}\text { Observed } \\
\text { failure mode }\end{array}$ \\
\hline B1 & - & 108.0 & - & 1.0 & Shear \\
B1-J & 315.3 & 322.3 & 214.3 & 1.3 & Shear \\
B2 & 29.9 & 36.4 & - & 5.0 & Flexure-Shear \\
B2-J & 41.5 & 55.2 & 18.8 & 11.0 & Flexure-Shear \\
B3 & - & 56.2 & - & 1.0 & Shear \\
B3-J & 69.8 & 84.0 & 27.8 & 23.2 & Flexure \\
B4 & - & 57.2 & - & 1.0 & Shear \\
B4-J & 69.3 & 79.9 & - & 21.7 & Flexure \\
B5 & 58.7 & 61.7 & 21.3 & 1.3 & Shear \\
B5-J & 70.8 & 83.0 & & 19.4 & Flexure \\
\hline
\end{tabular}

the shear failure mechanism, and as this ratio decreases, the shear strength considerably increases due to the arch action.

\section{Theoretical Analysis}

Estimations of the flexural and shear strength of the tested beams are also included in this study in order to provide an element of comparison and further discussion of the test data. Further, this theoretical analysis aims to the evaluation of the monolithic factors for the capacity at yield and at ultimate of the jacketed beams. Table 6 presents the calculated values of the following loads considering the used test setup of a simply supported beam with two symmetrical concentrated loads at mid span and a clear shear span of $a=$ $600 \mathrm{~mm}$ :

$$
\begin{aligned}
& P_{M y, \text { calc }}=\frac{2 M_{y, \text { calc }}}{a}, \\
& P_{M u, \text { calc }}=\frac{2 M_{u, \text { calc }}}{a} \\
& P_{V u, \text { calc }}=2 V_{u, \text { calc }},
\end{aligned}
$$

where: $P_{M y \text {,calc }}$ : load that corresponds to the calculated flexural capacity at yield $\left(M_{y, \text { calc }}\right), P_{M u \text {,calc }}$ load that corresponds to the calculated flexural capacity at ultimate $\left(M_{u, \text { calc }}\right)$, and $P_{V u \text {,calc }}$ : load that corresponds to the calculated maximum shear capacity $\left(V_{u, \text { calc }}\right)$.

The above mentioned flexural and shear capacities of the tested beams have been calculated using the modified compression field theory (MCFT) and by implementation of the software package Response-2000 [22, 23]. Response2000 is the name of the sectional analysis program that was developed at the University of Toronto by Bentz under the supervision of Collins [23]. The shear capacity of the beams has also been estimated using the theoretical analysis proposed by Zararis and Papadakis [24-26] (see the values of $P_{V u \text {, calc-Z }}$ in Table 6).

The comparisons between the calculated values of the load at yield and at ultimate due to flexure, $P_{M y \text {,calc }}$ and
$P_{M u, \text { calc }}$, respectively, and due to shear, $P_{V u \text {,calc }}$, indicate the potential (or "expected") failure mode of the tested beams, as reported in Table 6. Specifically, "flexure" derives when the "weak" component is the flexural strength and the calculated load of the ultimate shear strength is higher than the load of the ultimate flexural capacity $\left(P_{M u \text {,calc }}<P_{V u \text {,calc }}\right)$. Thus, a flexural response is expected and the calculated yield load equals to the load of the flexural strength at yield $\left(P_{y, \text { calc }}=\right.$ $\left.P_{M y \text {,calc }}\right)$, whereas the calculated maximum load equals to the load of the ultimate flexural strength $\left(P_{\text {max,calc }}=P_{M u, \text { calc }}\right)$. Further, "shear" comes when the "weak" component is the shear strength and the load of the flexural strength at yield is higher than the load of the ultimate shear capacity $\left(P_{V u \text {,calc }}<\right.$ $\left.P_{M y, \text { calc }}\right)$. This way, a shear response is expected and the calculated maximum load equals to the load of the ultimate shear capacity $\left(P_{\text {max,calc }}=P_{V u \text {,calc }}\right)$. The combination of "flexure-shear" derives when the calculated load of the ultimate shear capacity ranges between the loads of the flexural strength at yield and at ultimate $\left(P_{M y, \text { calc }}<P_{V u \text {, calc }}<\right.$ $\left.P_{M u, \text { calc }}\right)$. Therefore, a rather combined response is expected and the calculated load at yield equals to the load of the flexural strength at yield $\left(P_{y, \text { calc }}=P_{M y \text {,calc }}\right)$, whereas the calculated maximum load equals to the load of the ultimate shear capacity $\left(P_{\max , \text { calc }}=P_{V u \text {,calc }}\right)$. It is deduced that in most of the examined beams the observed and the expected failure mode from Tables 5 and 6 , respectively, are in a very good agreement.

A good agreement is also achieved between the experimental and the calculated values of the loads at yield and at maximum capacity of the initially tested beams (see the ratios of the experimental to the calculated load values $P_{y, \exp } / P_{y \text {,calc }}$ and $P_{\max , \exp } / P_{\max , \text { calc }}$ in Table 6 for the initial beams B1, B2, $\mathrm{B} 3, \mathrm{~B} 4$, and $\mathrm{B} 5$ ).

The analytical results presented in Table 6 concern both the initial and the jacketed beams. The calculated values of the loads at yield and at maximum capacity of the jacketed beams are used in order to evaluate the monolithic factors related to the strength of the beams. For this reason, simplified analyses have been performed for the case of the retrofitted beams assuming an identical geometry and a uniform concrete cross-section with the characteristics of the concrete of the initial beams. All the steel reinforcements 


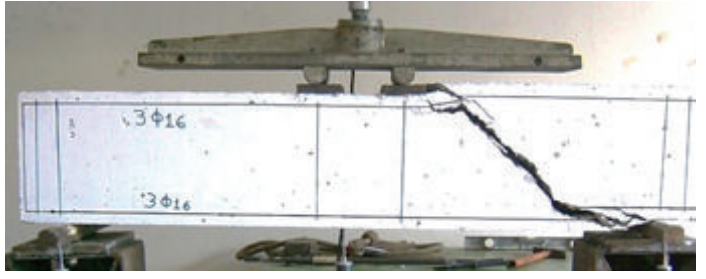

Specimen B1

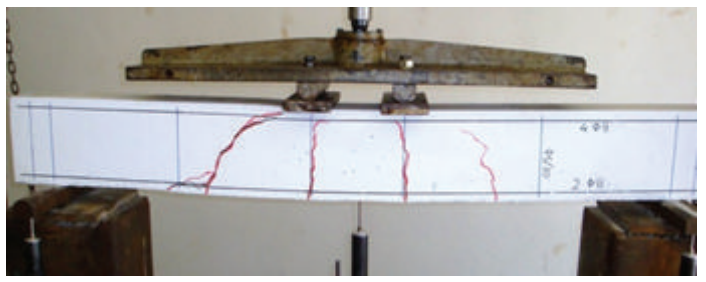

Specimen B2

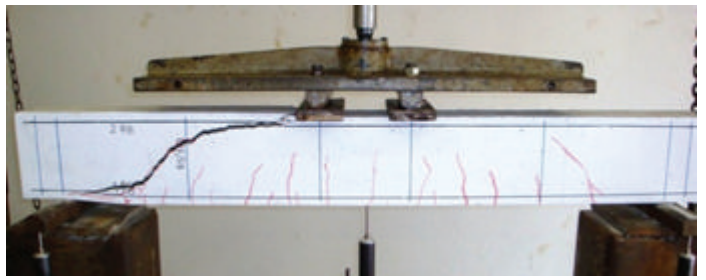

Specimen B3

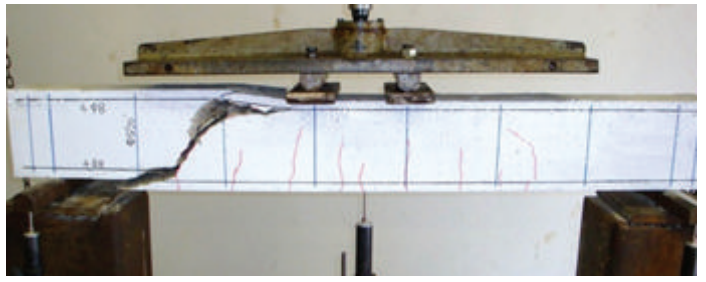

Specimen B4

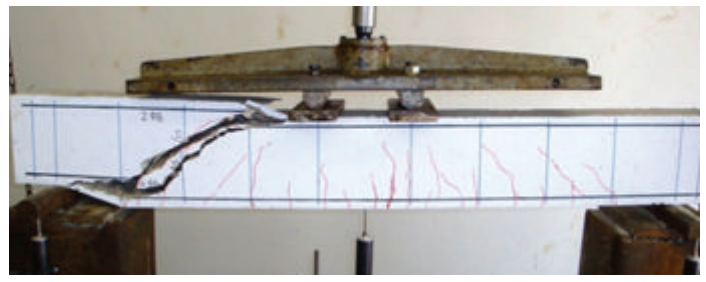

Specimen B5

Initially tested beams

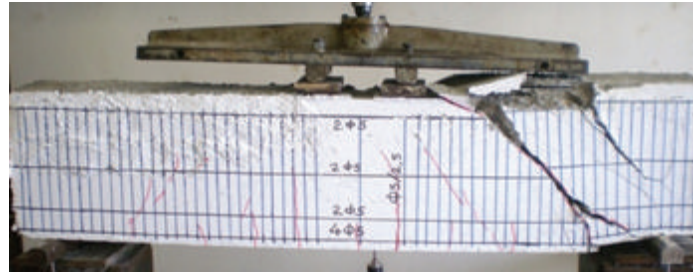

Specimen B1-J

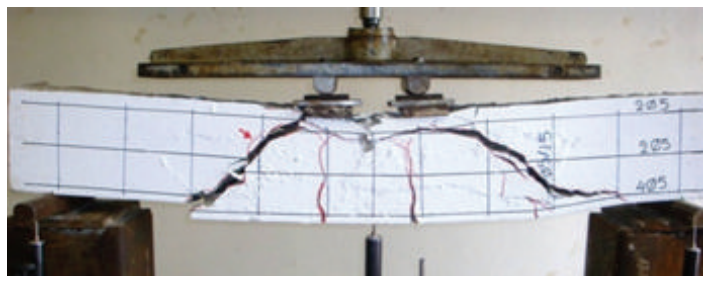

Specimen B2-J

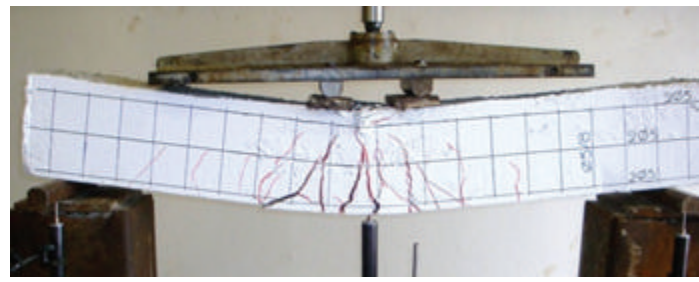

Specimen B3-J

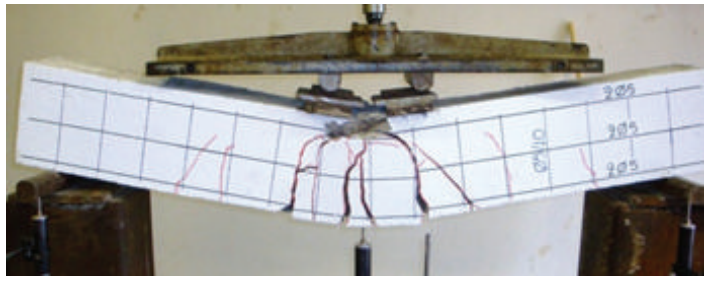

Specimen B4-J

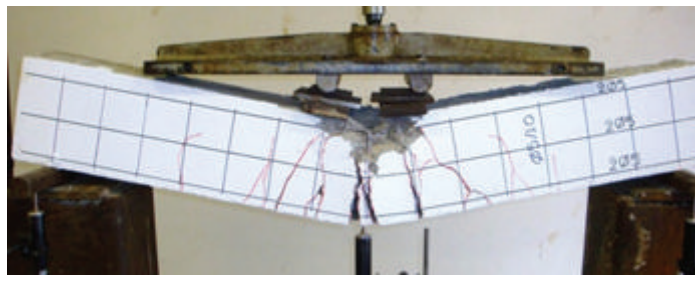

Specimen B5-J

Jacketed beams

FIgURE 7: Cracking patterns at failure of the tested beams.

of the initial beam and the jacket have been counted in the analyses. Analysis of a layered composite beam, the properties of the SCC, the damages of the initial beam, the shear transfer, and the relative slip at the interface between the initial concrete and the SCC of the jacket have not been taken into account. The analytical results presented herein have been derived from existing theoretical expressions. The calculated load values of the jacketed beams shown in Table 6 present the monolithic factor for the load at yield, $k_{y}$ and for the maximum load, $k_{\max }$.
It is known that for practical purposes, response indices of the jacketed members such as resistance and deformation measures at yielding and ultimate are routinely obtained by applying pertinent multipliers on the respective properties of monolithic members with identical geometry. The multipliers are referred to in the literature as monolithic factors. Monolithic factors are used by codes of practice for convenience, as the mechanics of composite action of jacketed RC members are too complicated for practical calculations [1]. 


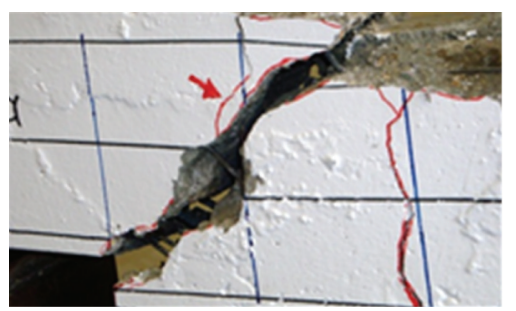

(a) B2-J (fracture of jacket's stirrup)

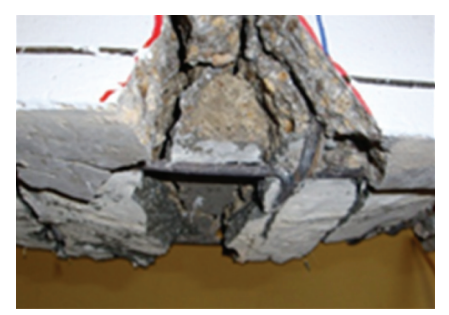

(b) B4-J (tension zone-interfacial slip)

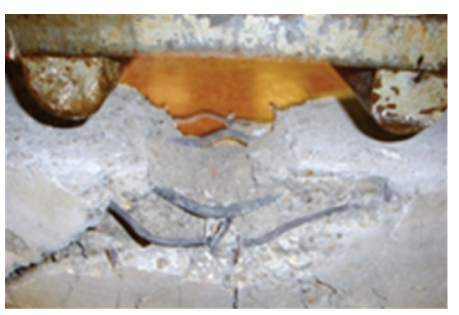

(c) B5-J (buckling of the compression bars)

FIgURE 8: Details of the jacketed beams at failure.

TABLE 6: Calculations and monolithic factors.

\begin{tabular}{|c|c|c|c|c|c|c|c|c|c|c|c|}
\hline $\begin{array}{l}\text { Beam } \\
\text { name }\end{array}$ & $\begin{array}{c}P_{M y, \text { calc }} \\
(\mathrm{kN})\end{array}$ & $\begin{array}{c}P_{M u, \text { calc }} \\
(\mathrm{kN})\end{array}$ & $\begin{array}{c}P_{V u, \text { calc }} \\
(\mathrm{kN})\end{array}$ & $\begin{array}{c}P_{V u \text { calc }-Z} \\
(\mathrm{kN})\end{array}$ & $\begin{array}{l}\text { Expecte failure } \\
\text { mode }\end{array}$ & $\begin{array}{r}P_{y, \text { calc }} \\
(\mathrm{kN})\end{array}$ & $P_{y, \exp } / P_{y, \text { calc }}$ & $k_{y}$ & $\begin{array}{c}P_{\max , \text { calc }} \\
(\mathrm{kN})\end{array}$ & $P_{\text {max }, \text { exp }} / P_{\text {max,calc }}$ & $k_{\max }$ \\
\hline B1 & 291.7 & 365.7 & 169.8 & 161.3 & Shear & - & - & - & 161.3 & 0.67 & - \\
\hline B1-J & 324.1 & 400.6 & 450.0 & 385.0 & Flexure-shear & 324.1 & - & 0.97 & 385.0 & - & 0.84 \\
\hline B2 & 31.2 & 39.5 & 59.2 & 39.2 & Flexure-shear & 31.2 & 0.96 & - & 39.2 & 0.93 & - \\
\hline B2-J & 47.2 & 56.7 & 96.8 & 91.2 & Flexure & 47.2 & - & 0.88 & 56.7 & - & 0.97 \\
\hline B3 & 60.4 & 67.2 & 54.8 & 51.0 & Shear & - & - & - & 51.0 & 1.10 & - \\
\hline B3-J & 70.3 & 79.7 & 118.0 & 130.4 & Flexure & 70.3 & - & 0.99 & 79.7 & - & 1.05 \\
\hline B4 & 60.7 & 73.9 & 64.2 & 56.2 & Shear & - & - & - & 56.2 & 1.02 & - \\
\hline B4-J & 70.0 & 84.8 & 107.2 & 122.7 & Flexure & 70.0 & - & 0.99 & 84.8 & - & 0.94 \\
\hline B5 & 60.4 & 67.0 & 66.6 & 64.3 & Flexure-shear & 60.4 & 0.97 & - & 64.3 & 0.96 & - \\
\hline B5-J & 69.9 & 79.7 & 101.6 & 131.1 & Flexure & 69.9 & - & 1.01 & 79.7 & - & 1.04 \\
\hline
\end{tabular}

Based on the values of the monolithic factor for the load at yield, $k_{y}$ and for the maximum load, $k_{\max }$ in Table 6 , it can be concluded that the jacketed beams B3-J and B5-J seem to act more or less monolithically since the values of $k_{y}$ and $k_{\max }$ are very close to 1.0. However, jacketed beams B1-J, B2-J, and B4-J appear to exhibit significant relative slip at the interface between the initial concrete and the SCC of the jacket. This can be also verified by the photographs of Figure 8 . Thus, a detailed analysis is required for the accurate prediction of the entire response of these retrofitted specimens.

\section{Concluding Remarks}

The experimental program of this study includes 10 monotonic four-point bending loading tests of 5 initial RC beams damaged in shear and after their rehabilitation using reinforced U-formed SCC jackets, these 5 retrofitted beams retested under the same loading. The main objective of this study is to investigate the application of this SCC jacketing technique to restore shear-damaged RC beams. Based on the test results presented herein, the following concluding remarks are drawn.

(i) The examined SCC jacketing seems to be an easy-toapply and rather effective rehabilitation technique for damaged RC beams since the capacity of the jacketed beams was fully restored or ameliorated with respect to the initially tested specimens. (ii) Significant increase of the loading bearing capacity that varied from $35 \%$ to $200 \%$ for the retrofitted beams with respect to the corresponding initial beams was observed.

(iii) The overall structural performance in most of the jacketed beams was substantially ameliorated regarding the initial shear-damaged specimens. Jacketed beams B3-J, B4-J, and B5-J exhibited pure flexural and enhanced ductile behaviour whereas the corresponding initially tested beams B3, B4, and B5 demonstrated typical brittle shear response. Furthermore, although the retrofitted specimen B2-J failed under a combined mode of flexure and shear, very alike that of the corresponding initial beam B2, the jacketed beam presented increased displacement ductility.

(iv) Deep beams B1-J and B1 displayed abrupt shear failure and severe diagonal cracking at the same position. Although the ultimate capacity of retrofitted beam B1-J has increased approximately 3 times with respect to the initially tested beam $\mathrm{B} 1$, questions about the ability of the SCC jacket to alter the brittle shear response of a deep beam to a more ductile one arise. Further, since beam B1 has larger cross-sectional dimensions than the other examined specimens, scale effect issues are also apparently raised. 
(v) Monolithic factors for the capacity at yield and at ultimate of the jacketed beams have been calculated and presented herein for practical purposes. Most of the examined retrofitted specimens exhibited relative slip at the interface between the initial concrete and the SCC of the jacket.

\section{Annotations}

$b, h$ : Width and height of the cross-section of the beam

$d: \quad$ Effective depth of the beam

a: $\quad$ Shear span of the beam

a/d: $\quad$ Span-to-depth ratio

$f_{c, \text { cyl }}$ : Mean cylinder compressive strength of concrete

$f_{c t, \text { split }}$ Mean splitting tensile strength of concrete

$\rho_{\ell \text {,tens }}$ : Ratio of the total steel longitudinal tension reinforcement

$\rho_{t}$ : $\quad$ Ratio of the total steel transverse reinforcement

$P_{y, \text { exp }}: \quad$ Experimental value of the load at yield

$P_{\text {max } \text { exp }}$ : Experimental value of the maximum load

$P_{\text {jack}}: \quad$ Experimental value of the load increase due to the jacketing

$\Delta_{y}: \quad$ Experimental value of the deflection at yield

$\Delta_{\max }: \quad$ Experimental value of the deflection at failure

$\Delta_{\max } / \Delta_{y}$ : Experimental value of displacement ductility

$P_{y \text {,calc: }}$ Calculated value of the load at yield

$P_{\text {max,calc: }}$ Calculated value of the maximum load

$P_{M y, \text { calc: }}$ Load that corresponds to the calculated flexural capacity at yield

$P_{M u \text {,calc }}$ : Load that corresponds to the calculated flexural capacity at ultimate

$P_{V u \text {,calc }}:$ Load that corresponds to the calculated maximum shear capacity

$P_{V u, \text { calc-Z }}$ : Load that corresponds to the calculated maximum shear capacity using the theoretical analysis proposed by Zararis and Papadakis [24-26]

$M_{y \text {,calc: }}$ Calculated flexural capacity at yield

$M_{u \text {,calc: }}$ Calculated flexural capacity at ultimate

$V_{u, \text { calc }}$ Calculated maximum shear capacity

$k_{y}: \quad \quad \quad$ Monolithic factor for the load at yield

$k_{\text {max }}$ : Monolithic factor for the maximum load.

\section{Acknowledgments}

The help and expertise on self-compacting concrete properties by K. K. Sideris, Associate Professor of Democritus University of Thrace, are gratefully appreciated. The contribution of C. P. Papadopoulos and D. Fotis, civil engineers, on the experimental project is also appreciated.

\section{References}

[1] G. E. Thermou, S. J. Pantazopoulou, and A. S. Elnashai, "Flexural behavior of brittle RC members rehabilitated with concrete jacketing," Journal of Structural Engineering, vol. 133, no. 10, pp. 1373-1384, 2007.

[2] S. N. Bousias, D. Biskinis, M. N. Fardis, and A. L. Spathis, "Strength, stiffness, and cyclic deformation capacity of concrete jacketed members," ACI Structural Journal, vol. 104, no. 5, pp. 521-531, 2007.

[3] F. Altun, "An experimental study of the jacketed reinforcedconcrete beams under bending," Construction and Building Materials, vol. 18, no. 8, pp. 611-618, 2004.

[4] A. G. Tsonos, "Lateral load response of strengthened reinforced concrete beam-to-column joints," ACI Structural Journal, vol. 96, no. 1, pp. 46-56, 1999.

[5] K. G. Vandoros and S. E. Dritsos, "Concrete jacket construction detail effectiveness when strengthening RC columns," Construction and Building Materials, vol. 22, no. 3, pp. 264276, 2008.

[6] A. D. G. Tsonos, "Performance enhancement of R/C building columns and beam-column joints through shotcrete jacketing," Engineering Structures, vol. 32, no. 3, pp. 726-740, 2010.

[7] G. E. Thermou, S. J. Pantazopoulou, and A. S. Elnashai, "Global interventions for seismic upgrading of substandard RC buildings," Journal of Structural Engineering, vol. 138, no. 3, pp. 387-401, 2012.

[8] T. Georgopoulos and S. E. Dritsos, "A steel jacketing technique for strengthening RC columns," in Proceedings of the 10th European Conference on Earthquake Engineering, pp. 22752280, Vienna, Austria, 1994

[9] C. E. Chalioris, "Torsional strengthening of rectangular and flanged beams using carbon fibre-reinforced-polymersexperimental study," Construction and Building Materials, vol. 22, no. 1, pp. 21-29, 2008.

[10] C. G. Karayannis and G. M. Sirkelis, "Strengthening and rehabilitation of RC beam-column joints using carbon-FRP jacketing and epoxy resin injection," Earthquake Engineering and Structural Dynamics, vol. 37, no. 5, pp. 769-790, 2008.

[11] T. C. Triantafillou and C. G. Papanicolaou, "Shear strengthening of reinforced concrete members with textile reinforced mortar (TRM) jackets," Materials and Structures, vol. 39, no. 285, pp. 93-103, 2006.

[12] D. A. Bournas and T. C. Triantafillou, "Flexural strengthening of reinforced concrete columns with near-surface-mounted FRP or stainless steel," ACI Structural Journal, vol. 106, no. 4, pp. 495-505, 2009.

[13] C. G. Karayannis, C. E. Chalioris, and G. M. Sirkelis, "Local retrofit of exterior RC beam-column joints using thin RC jackets-an experimental study," Earthquake Engineering and Structural Dynamics, vol. 37, no. 5, pp. 727-746, 2008.

[14] K. H. Khayat, "Workability, testing, and performance of selfconsolidating concrete," ACI Materials Journal, vol. 96, no. 3, pp. 346-353, 1999.

[15] A. S. Georgiadis, K. K. Sideris, and N. S. Anagnostopoulos, "Properties of scc produced with limestone filler or viscosity modifying admixture," Journal of Materials in Civil Engineering, vol. 22, no. 4, pp. 352-360, 2010.

[16] T. Albanesi, D. Lavorato, C. Nuti, and S. Santini, "Experimental tests on repaired and retrofitted bridge piers," in Proceedings of the International FIB Symposium, pp. 673-678, Amsterdam, The Netherlands, 2008.

[17] C. G. Fakitsas, P. E. A. Papakonstantinou, P. D. Kiousis, and A. Savva, "Effects of recycled concrete aggregates on the compressive and shear strength of high-strength self-consolidating concrete," Journal of Materials in Civil Engineering, vol. 24, no. 4, pp. 356-361, 2012. 
[18] K. M. Heiza, N. N. Meleka, and N. Y. Elwkad, "Behavior and analysis of self-consolidated reinforced concrete deep beams strengthened in shear," Journal of ISRN Civil Engineering, vol. 2012, Article ID 202171, 14 pages, 2012.

[19] K. K. Sideris, A. S. Georgiadis, N. S. Anagnostopoulos, and P. Manita, "Low strength self compacting concrete for building application," in Proceedings of the International FIB Symposium, pp. 1057-1059, Amsterdam, The Netherlands, 2008.

[20] C. G. Karayannis, C. E. Chalioris, and K. K. Sideris, "Effectiveness of RC beam-column connection repair using epoxy resin injections," Journal of Earthquake Engineering, vol. 2, no. 2, pp. 217-240, 1998.

[21] C. E. Chalioris, C. N. Pourzitidis, C. P. Papadopoulos, and D. Fotis, "Flexural rehabilitation of RC beams using selfcompacting concrete jacketing," Proceedings of the 2nd International Conference on Civil Engineering and Building Materials, Hong Kong, 2012, Paper ID 257.

[22] F. J. Vecchio and M. P. Collins, "The modified compression field theory for reinforced concrete elements subjected to shear," Journal of the American Concrete Institute, vol. 83, no. 2, pp. 219-231, 1986.

[23] E. Bentz and M. P. Collins, Response-2000 Reinforced Concrete Sectional Analysis Using the Modified Compression Field Theory, Version 1. 0. 5, Software Package, University of Toronto, 2000.

[24] P. D. Zararis, "Shear compression failure in reinforced concrete deep beams," Journal of Structural Engineering, vol. 129, no. 4, pp. 544-553, 2003.

[25] P. D. Zararis and G. C. Papadakis, "Diagonal shear failure and size effect in RC beams without web reinforcement," Journal of Structural Engineering, vol. 127, no. 7, pp. 733-742, 2001.

[26] P. D. Zararis, "Shear strength and minimum shear reinforcement of reinforced concrete slender beams," ACI Structural Journal, vol. 100, no. 2, pp. 203-214, 2003. 

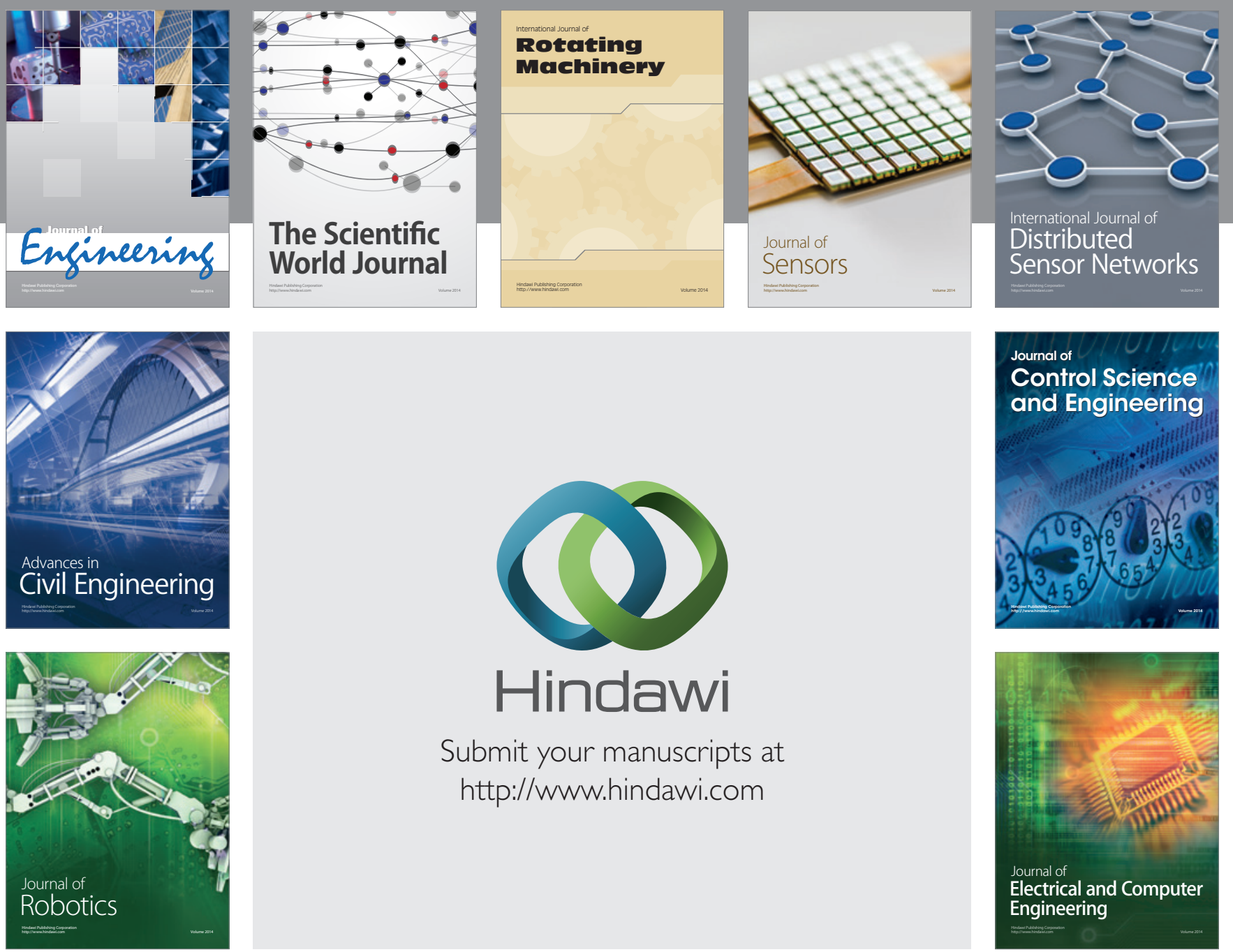

Submit your manuscripts at

http://www.hindawi.com
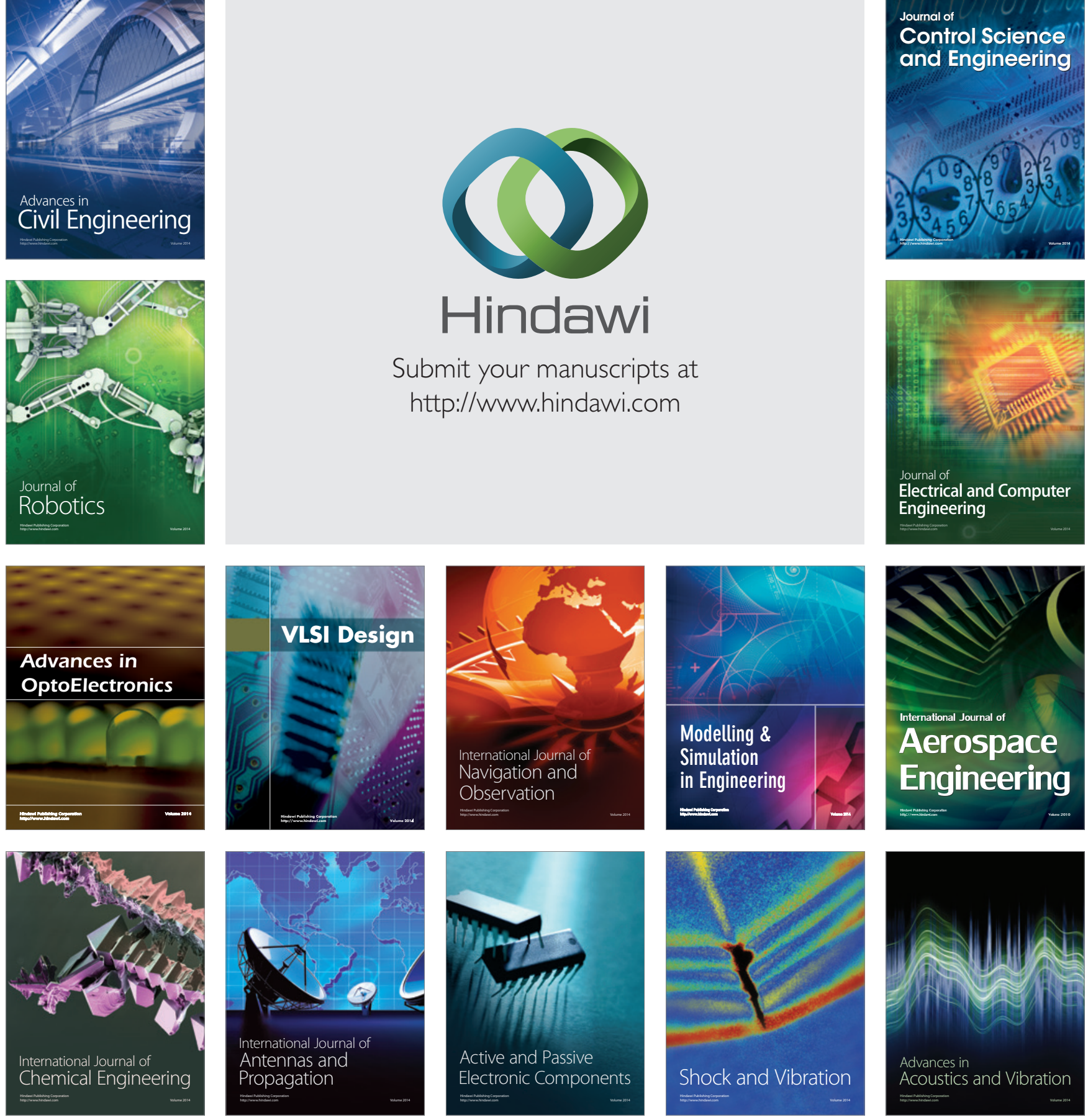